\title{
LEITURA DO CONCEITO HEIDEGGERIANO DE "COISA"
}

\section{MIGUEL ANTONIO DO NASCIMENTO ${ }^{1}$}

RESUMO: Este artigo consiste em leitura do conteúdo de "coisalidade" como questão própria ao conhecimento filosófico. O desenvolvimento do assunto é constituído de investigação e argumentação baseadas no contexto do questionamento filosófico do conceito de coisa estabelecido por Heidegger em seu escrito A questão da coisa (Die Frage nach dem Ding). O questionamento diz respeito ao que o homem estabeleceu historicamente como verdade sobre o mundo através do conhecimento. O conteúdo correspondente à verdade está sendo considerado, por Heidegger, já discutido pela tradição histórica da filosofia. É considerado também que, mesmo assim, ainda não foi com isso compreendido nem discutido aquilo que é mais significativo e digno de ser concebido; e que deve ser desenvolvido como questão estabelecida ao se tratar do conceito de coisa.

PALAVRAS-CHAVE: Heidegger. Questão da coisa. Historicidade. Verdade.

ABSTRACT: This article consists of reading the content of "thingish" as a matter of philosophical knowledge. The development of the subject is consisted in the investigation and argumentation based on the framework of the philosophical questioning of the concept of thing established by Heidegger in his writing "The Question of the Thing" (Die Frage nach dem Ding). The questioning concerns what man has historically established as truth about the world through knowledge. The content corresponding to the truth is considered, by Heidegger, as already having been discussed by the historical tradition of philosophy. However, it is also considered that, even then, that which is most significant and worthy of conceiving has not yet been understood or discussed; and that it must be developed as an established question when dealing with the concept of thing.

KEYWORDS: Heidegger. Question of the thing. Historicity. Truth.

O significado filosófico de questão, relativo ao conceito de coisa, aparece enfatizado por Heidegger em seu escrito Die Frage nach dem Ding - título traduzido aqui por A questão da cois $a^{2}$. Para este fato está voltado o desenvolvimento do assunto abordado no presente artigo.

\footnotetext{
${ }^{1}$ Professor Associado de Filosofia da Universidade Federal da Paraíba (UFPB). Doutor em Filosofia pela Universidade Federal do Rio de Janeiro (UFRJ). E-mail: migueln.ufpb@gmail.com.

${ }^{2}$ Apenas para distinção específica terão aspas os termos "coisa" e "coisalidade" e as expressões "questão da coisa", "questão acerca da coisa", "pergunta pela coisa" e "caráter histórico"; num caso e no outro serão compreendidos com o sentido dado por Heidegger. Outrossim, todas as passagens citadas da obra de Heidegger Die Frage nach dem Ding (HEIDEGGER, 1962) são traduções nossas.
} 
$\mathrm{Na}$ composição de seu texto, Heidegger apresenta uma parte preparatória intitulada "Diversas maneiras de perguntar pela coisa", seguida da outra parte, a principal, intitulada por ele "Maneira kantiana de perguntar pela coisa". Pode parecer então que o conteúdo subentendido no termo "principal" deva concernir propriamente à compreensão kantiana daquilo que precisa valer objetivamente no conceito filosófico de coisa. Mas o que está em jogo aí concerne primordialmente ao entendimento que Heidegger possui deste conteúdo ao ser comparado com o entendimento de Kant. Por isso também é só aparentemente que tal parte "principal" pode ser considerada como tal, no que diz respeito a Kant; concerne, antes, à interpretação que Heidegger faz do entendimento que Kant teria tido do referido conteúdo.

Mas isso é assim não precisamente em razão da diferenciação que se possa estabelecer entre um pensador e outro; é antes porque o que se encontra sob questionamento - seja para Heidegger ou Kant, mas também para qualquer filósofo - é aquilo que o homem toma por verdade, enquanto lida com as coisas constitutivas do mundo em que ele vive. Reside neste fato a razão de se falar em significado de questão enquanto questão da coisa e na ênfase para com o destaque correspondente. Com base nisso convém aqui, mais especificamente, nos voltarmos já desde o início para aquilo que está em debate na compreensão do conceito filosófico de coisa. Heidegger mesmo, ao se manifestar sobre isto no decorrer do escrito, confirma a intenção de alcançar a "compreensão da obra toda" de Kant, mas acrescenta: "Mas também este compreender serve apenas para exame de elucidar a questão 'Que é uma coisa"' (HEIDEGGER, 1962, p. 96).

Tomada assim a perspectiva para o entendimento do assunto em jogo, meu propósito é apresentar uma leitura da parte denominada por Heidegger "preparatória". Trata-se da especulação filosófica que ele estabelece com relação à importância histórica daquilo que se fez valer como concepção do sentido de coisa, desde a antiguidade, e também na modernidade e contemporaneidade. Em resumo, procuro tornar mais significativo o que Heidegger toma por fundamental nisso, desde o que é preestabelecido por ele e feito predominar como conteúdo em causa na parte "preparatória"; a outra parte de seu escrito é aqui apenas aludida como extensão disso.

1.

Para começo e ordem no desenvolvimento do assunto posto, enfatizo o fato de se poder designar as coisas com o termo coisa; destaco a designação de coisa ocorrer no que tomamos por coisa uma coisa. No caso tendemos a nos indagar, por que isso se dá justamente 
assim - como se coisalidade fosse um ato, identificado em cada coisa. Pode acontecer de sermos indiferentes a isso; de não pensarmos nisso. Se, porém, não estacionarmos em tal indiferença, se interrogarmos por que isso é desse modo, então estaremos sempre a atingir o próprio indagar sobre a coisalidade intrínseca à condição de coisa; ou seja, ocorre de se querer saber por que isso é deste modo assim como é. O fato em destaque refere-se, consequentemente, à compreensão do vínculo entre o que tomamos por coisa - por ser algo designado material ou não material - e o que não é designado deste modo, por ser algo que desde sempre é já a referência intrínseca para o que recebe designação de coisa, mas não se manifesta do mesmo modo.

O referido vínculo ocorre, portanto, como o que há de mais essencial por ser sempre antecipação; é a referência admitida ao que quer que se designe, materialmente ou não, no compreender por coisa uma coisa; é conexão primordial que estabelecemos entre o que se adota por coisa e sua procedência referencial, mas que só é percebida caso se busque justificála como origem em cada coisa.

Caso não nos indaguemos sobre tal origem, mantemo-nos na indiferença relativa ao quê e por que é tudo tal como é. Aparenta então tratar-se de algo que não tem começo ou não requer ser pensado em sua procedência. O resultado é percebermos somente um lado dessa conexão: nós não nos pomos necessariamente na condição de fazer valer o outro lado - o da referência subentendida que, entretanto, se mantém ocultada. Situação em que, ao mesmo tempo, nos leva a nos indagarmos sobre essa condição de origem da designação para significado de coisa. O entorno disso é referido por Heidegger nestes termos: "A partir de onde devemos decidir o ser-coisa da coisa?” (HEIDEGGER, 1962, p. 11). Se tentarmos dar a resposta e começarmos pela validade de designação em toda coisa determinada, não é o suficiente - não atingimos a origem do ser de tal coisa. Permaneceremos com a interrogação posta ou nos recolheremos na indiferença. Nesta compreensão, Heidegger descreve até onde é possível chegarmos. Três graus na compreensão são empregados por nós: a) Chamamos coisa a tudo que está concretamente ao nosso alcance. Exemplo: livro, giz, Pedro, madeira, folha, água, etc. b) Chamamos coisa também às resoluções, convicções, planos, feitos, modo de pensar, etc. c) Chamamos coisa ainda a todas as coisas, no sentido de tudo aquilo que seja algo e não nada.

Mas de pronto não conseguimos dizer que sentido de coisa é empregado para exprimirmos a condição de coisalidade em cada coisa. Entretanto, é precisamente isto - esta condição - o que nos faz poder chamar de coisa, seja o que está próximo de nós ou muito 
distante. Trata-se de "algo que faz em uma [coisa] tal, a coisa enquanto coisa, não enquanto pedra e enquanto madeira; algo que torna coisa a coisa" (HEIDEGGER, 1962, p. 7).

Relativamente a tal circunstância, o termo "coisa" fica a ocupar o lugar do elemento que deve definir a realidade a que se vincula. Em outros termos: falamos de coisa e coisalidade em razão de algo mais amplo que não se mostra todo e de uma vez e que, assim, se deixa transparecer no caráter de coisa das coisas que a constituem. Quando nos interessamos em examinar o caráter de coisa nas coisas, isto é, se interrogamos quanto à coisalidade, ou se somos indiferentes a isso, no fundo estamos apenas recorrendo ao modo de acesso ao que não se dá todo de uma vez e sempre se mostra como esse todo que não se deixa limitar, nem se reduzir a "nada".

Nisso também estamos a fazer com que o termo "coisa" exprima o obstáculo maior que encontramos na tentativa de que a realidade vire um todo que precisamos dominar com o conhecimento. Isto quer dizer: como não temos evidências concretas que nos informem o que seja esta realidade, falamos dela indagando: que coisa é esta realidade em que nos encontramos? O termo coisa toma o lugar da explicação que, enquanto explicação da respectiva realidade, falta. Por isso, passa a ser importante aqui dizer que são, na verdade, muitos os sentidos em que falamos de uma única e mesma coisa - esta mesma realidade que buscamos definir. $\mathrm{O}$ objetivo é ir dando a indicação de que é esta única realidade o tipo possível de coisa que queremos tratar, visando defini-la. O termo definir, no entanto, implica submeter a limite, fim e findar. Neste sentido, vê-se que, com a noção de questão relativa a coisa, o propósito é identificar uma ambivalência e tratá-la como paradoxo. Pois, sempre que recorremos ao termo coisa, para indicação de proximidade e limitação pela qual determinado ente pode ser atingido por nosso conhecimento, isso precisa garantir o seu contrário - sua condição de começo ou origem, bem como sua indicação de fim como significado limite ou de finalidade última.

A compreensão deste vínculo tem em vista fortalecer a referência ao que se define como coisa designada, para que esta não reste negada ou falsificada e, principalmente, não se extinga. Pois, logo que não se consegue de pronto definir aquilo que dá procedência à designação das coisas, uma alternativa é decidir-se pela negação de sua verdade. No entanto, a referência à origem é fortalecida por ela não se dizer em razão do já efetivado como coisa nas coisas, mas necessariamente por ter de ser desde sempre procedente. Procedente do que é sempre determinação. Nesta compreensão destaco indicação de Heidegger de que, no que 
perguntamos pelo quê da coisalidade - e é o que sempre nos ocorre de fazê-lo - atingimos “aquilo que uma coisa como tal determina a ser uma coisa” (HEIDEGGER, 1962, p. 8).

Neste nível de entendimento convém ampliar a noção de "questão" nisso. Mais exatamente, joga-se aqui com a possibilidade de mostrá-la através de descrição da própria realidade em que as coisas se dispõem na constituição de mundo. Com isso obtém-se e mantém-se a determinação do todo de mundo, à qual se vincula o conteúdo de questão. Sem dúvida, o que diz questão nisso não é já o mundo em totalidade, mas sim o significado de verdade, intrínseco à referida determinação. Significa dizer que o conteúdo relativo à questão como tal é alcançado enquanto a possibilidade de determinação constitutiva do mundo. Mostra-se com nossa noção de totalidade do mundo; mostra-se como o todo, mas não por que se conheça a consistência e detalhes de seus componentes.

Mas, mais importante na compreensão do conteúdo de questão é perceber que esta não se define apenas pelo que informa Heidegger nisso. Devemos dizer que a questão e seu conteúdo preexistem a Heidegger. Seu conteúdo consiste no teor de complexidade, que consiste no fato de o pensar humano não lhe poder ser indiferente. Devemos reconhecer neste teor de complexidade justamente aquilo que tomamos por filosófico. E, em seguida, dizer também que a complexidade reside nos modos e tentativas de compreendê-lo. É o mesmo que dizer: o aspecto enigmático disso deve ser atribuído ao nosso compreender e não já ou propriamente ao referido conteúdo filosófico em si. O significado da verdade que se costuma vincular ao sentido enigmático de "amor à sabedoria", apresentado por Pitágoras, continua sendo aí o próprio teor de complexidade do conceito de coisa a que se refere Heidegger.

Compreende-se Heidegger dizer que a questão sobre a coisa é já muito antiga e que o que nela é sempre novo é só o fato de ter de ser posta sempre mais uma vez (Cf. HEIDEGGER, 1962, p. 1). Devemos ressaltar, porém, alguns elementos desta declaração para fortalecer o significado do saber filosófico na conveniência que devemos adotar aqui. Por exemplo, é dito que se trata de uma questão que é, de um lado antiga, talvez até a mais antiga de todas; de outro lado isto quer dizer que é a mais nova de todas, no sentido de que sua importância se reduz propriamente a ter de ser incessantemente posta mais uma vez; e ainda é preciso dizer que se trata de uma questão, quer dizer, de uma polêmica aberta, dado que a coisa mesma não se conformou ainda a nenhuma determinação ou delimitação ou definição. Esses pontos isolados estão a mostrar e confirmar o enigma relativo ao conteúdo de filosofia, no sentido de que se trata de algo que desde sempre já está aí a se mostrar, mas não tem sua 
verdade assegurada por este fato de se mostrar tal como se mostra. Seria, justamente, o contrário disso, se se quisesse identificar na filosofia algo por onde começar ou findar.

$\mathrm{Na}$ alusão que o autor faz a Tales, em relação ao que lhe teria dito uma criada, tanto Platão quanto Heidegger assegura um distanciamento significativo entre as coisas próximas de nós e aparentes e uma outra coisa que se dá a conhecer através destas, mas que não é da mesma categoria que elas. Sobretudo não é uma coisa, não é algo e sim o próprio ter de ser sempre aquilo que está sendo como coisa. Assim é que alguém como Tales, que aqui significa o filósofo, pode perceber isso que está sendo o que é no e enquanto conceito de coisa; e ao mesmo tempo, porém, alguém - a criada, que significa aqui o entorno ao âmago do questionar filosófico na questão; o entorno do qual fazem parte inclusive todos os conhecimentos que tratam das coisas como coisas objetivas e assim as definem - não o percebe. É significativo que, em relação a este elemento em questão, Heidegger se refira ao termo "metafísica". Ou seja, a tentativa desse conhecimento de se assegurar como saber filosófico ganhou esta designação de metafísico, isto é, conhecimento do para além dessas coisas físicas aparentes. Metafísico seria a designação para aquele distanciamento de que falam Heidegger e Platão a respeito de Tales.

Mas o interesse aqui é sobretudo caracterizar o conteúdo preso ao que permanece aí velado e complexo. Por isso, a metafísica surge em princípio como a denominação adequada ao conteúdo do filosófico, posto que exprime bem o caráter de "separação" entre as coisas aparentes e algo complexo, enigmático e irredutível ao que é aparente. Mesmo Kant, como um crítico da própria metafísica, isso já na modernidade, ratifica esta denominação adequada, no momento em que se refere a duas dimensões da realidade, a coisa em si e o fenômeno. Nas palavras de Heidegger: "Em consequência disso, Kant fala, por exemplo, da 'coisa em si' e na verdade, numa diferenciação da 'coisa para nós', quer dizer, como fenômeno. Uma coisa em si é algo que não é acessível para nós homens, através da experiência, assim como uma pedra, uma planta ou um animal" (HEIDEGGER, 1962, p. 4). No entanto, a designação "metafísico", em princípio adequada para o saber filosófico, sempre só ratifica a verdade como o que está ocultado, uma vez que mostra a impossibilidade do acesso ao enigma desse conteúdo em questão. Na verdade, consagra-o como inacessível ao defini-lo como algo em si.

$\mathrm{Na}$ contemporaneidade passa-se a perceber, mais claramente e mais criticamente, a definição da verdade a significar uma consagração do modo do auto-ocultar-se. Passa a se investir então num modo de acesso e desvelamento do que se mostra ocultado. Significado esse coincidente aqui com a referência tácita de que a criada "queria dizer-nos que 
deveríamos, antes de mais, prestar atenção ao que se passa à nossa volta" (HEIDEGGER, 1992, p. 18). Se for assim mesmo, então dependemos essencialmente do que está em torno de nós, porque estamos irremediavelmente conectados ao que compreendemos com o auxílio dos conhecimentos metodológicos; e, paradoxalmente, a respectiva compreensão vem de que conseguimos não nos reduzir a compreendermos assim - conforme validamos pela demonstrabilidade científica. Por isso, tal ambivalência nisso nos leva ao entendimento de que precisamos de um outro caminho enquanto tratamento do conteúdo do saber filosófico.

Nisso se encontra o nexo significativo do propósito de pôr em desenvolvimento a compreensão da questão da coisa: seria preciso superar toda incompreensão relativa à coisalidade nas coisas, e não aceitar reduzi-la ao entendimento reconhecido pela garantia de sua validade dada pelo saber de ciência ou outro tipo de conhecimento. Por causa disso, Heidegger nos leva a dizer que a questão da coisa possui sua verdade somente reconhecida em sua identidade histórica. Neste sentido, quer seja na abertura do escrito mencionado ou no respectivo fim, o registro disso se deixa ser tomado por nós como indicação deste fato. Nele está dito que se trata de uma questão que é antiga, "tão antiga como o começo da filosofia com os Gregos no século VII a. C"; razão também de se dever "caracterizá-la pelo seu lado histórico" (HEIDEGGER, 1962, p. 2).

Mas este sentido de histórico é todo peculiar e específico: quase não diz nada dos significados conhecidos de história. Disso encontra-se apenas o ter de alcançar a compreensão de antigo - mas assim mesmo para dizer que se trata do que se consegue entender como o que é mais antigo de tudo; e é só para tentar passar dessa compreensão para outra não induzida pela experiência de tempo nossa e usual: como o acontecimento do que já está dado para nós e em que atuamos enquanto estamos sendo o que conseguimos ser. Neste sentido é confirmada, por fim, a importância do conteúdo de histórico que reside na coisalidade. Enquanto questão de "caráter histórico" está em jogo nela "não o como foi outrora, e sim como é no essencial ainda hoje" (HEIDEGGER, 1962, p. 32).

Proposta de um outro caminho enquanto o filosofar - é assim que devemos então ler esse escrito de Heidegger. Parece ter valor examinar mais de perto que conteúdo fílosófico pode ter a indicação de que se deveria "prestar atenção ao que está à nossa volta". Mas nisso há uma espécie de ambiguidade paradoxal: ao mesmo tempo em que se requer o conteúdo filosófico de distanciamento, exige-se considerar o mais próximo, o que está "à nossa volta". Já ao se dizer qual "conteúdo filosófico" reside naquilo que está ao redor de nós, já nisso estamos a dizer que não se trata da consistência e aparência das coisas pura e simplesmente e 
sim daquilo que torna determinada coisa a "coisa" que ela é. Por isso Heidegger fala assim: “[...] buscamos algo que faz em uma [coisa] tal, a coisa enquanto coisa, não enquanto pedra e enquanto madeira; algo que torna coisa (be-dingt) a coisa" (HEIDEGGER, 1962, p. 7).

2.

Para o passo seguinte, no desenvolvimento do assunto posto, convém retomar o caráter ambíguo acima referido. Requer citar a segunda parte da afirmação paradoxal correspondente. O intuito aqui é fazer aparecer o conteúdo que gera a ambiguidade referida na compreensão de coisalidade. Momento em que Heidegger indica outra maneira de tratar a questão da coisa como simplesmente tornar conhecidas as coisas dadas: "[...] pomos esta questão apenas para saber o que é uma pedra, um lagarto, [...] um broto de grama, [...] um canivete, [...]" (HEIDEGGER, 1962, p. 7).

É verdade que permanece na posição primordial a primeira parte desta afirmação, a saber: "o que faz a coisa ser coisa enquanto tal". Mas importa também dar destaque à relação entre o saber relativo à coisalidade e o relativo aos métodos científicos e técnicos. Pois, todo conhecimento específico pode definir um objeto correspondente com mais eficácia de validade objetiva. E também porque não se trata de duas realidades, mas sim de uma única razão da ambiguidade. Num exemplo dado por Heidegger, a botânica, a mineralogia, a geometria, etc., podem, com mais propriedade, definir, respectivamente, a planta, a pedra, o triângulo. A conclusão a chegar é: Em última instância, todo filósofo é levado a tratar da questão da coisa para saber e poder dizer o que é uma coisa. É o mesmo conteúdo que se faz presente no dizer da "criada" em relação a Tales de Mileto: nunca deixar de "prestar atenção à nossa volta" (HEIDEGGER, 1992, p. 18).

Além disso, Heidegger não considera que o saber para a coisalidade exista fora deste nosso trato com as coisas, que implica o próprio âmbito de nossa experiência com a ciência. Em outros termos, o objeto deste saber se encontra no mesmo mundo onde está também todo saber. "Nossa experiência e nossa opinião cotidianas das coisas, isso é, em todo o caso, daí" (HEIDEGGER, 1962, p. 9). Ele compara nisso a experiência quotidiana e a experiência científica da coisa, buscando examinar a verdade da coisa a partir de ambas as experiências. Assim acaba por fortalecer isto: com o poder da certeza inerente ao moderno conhecimento de demonstrabilidade, a coisalidade faz progredir o interrogar acerca da verdade da coisa.

Dito isso, é preciso, porém, verificar e explicar a diferença de tratamento entre os dois modos de conhecer - o da filosofia e o das ciências; como também entre o entendimento 
heideggeriano disso e o dos pensadores na modernidade. Devemos considerar o fato de Heidegger fazer valer na mesma afirmação duas coisas aparentemente opostas e no modo de ambivalência: aquilo a que precisamos ter acesso não se dá nunca fora das coisas, mas também nem por isso são meramente essas mesmas coisas. Para Heidegger devemos saber dessas coisas exatamente o que "o mineralogista, o botânico, o zoólogo... não querem saber" ou não tenham de saber (HEIDEGGER, 1962, p. 7). Mas ele mesmo diz que isso não quer dizer que saibamos o lugar-onde depararmo-nos com "aquilo a que queremos ter acesso" (HEIDEGGER, 1962, p. 7). Ele apenas avisa que esse lugar-onde resulta numa conjuntura em que nós, isto é o homem, temos de partir dela; e ela consiste em que as coisas só se mostram particularizadas e só a partir disso surge aquilo a que se quer ter acesso, no momento em que é tornado universal pelo homem. Aquilo a que se quer ter acesso, portanto, nunca poderia se encontrar em algum lugar e sim apenas em nós, no sentido do próprio acesso que estabelecemos.

Convém, então, registrar a nitidez diferencial entre o que temos de compreender segundo o alcance e recursos do saber metodológico das ciências e o saber de busca da verdade segundo o exercício da reflexão filosófica. Se algum filósofo quiser empregar o mesmo tipo de conhecimento específico, nunca vai obter êxito, visto que não busca algo concreto e consistente como o são estes objetos conhecidos pela ciência. Para a pergunta inevitável, se se trata de um saber mais importante do que a ciência, Heidegger diz, porém, que não é um saber que possa "substituir, nem melhorar as ciências" (HEIDEGGER, 1962, p. $8)$.

Um ponto a considerar sobre como encontrar a verdade dessa "coisa" é mostrado por Heidegger quando exemplifica o tratamento da mesma realidade quotidiana observada pelo astrofísico (homem de ciência) e pelo pastor (homem do senso comum e de conhecimento poético). Ambos observam o sol, que cotidianamente aparece e desaparece. Para o pastor, o sol efetivo é este que vê a cada dia, este que para o astrofísico mostra, "a cada dia", só sua mera aparência; efetivamente, o sol de verdade nada tem de alguns desses elementos que aparenta ter, como nascer e se pôr, mover-se, etc. A verdade do astrofísico, porém, nem por isso é suficiente. Pois, se ela diz como o sol é, realmente, não diz, no entanto, sua razão de ser assim como é, por que é assim e não de outro modo nem para que fim em relação à destinação que o homem concebe. E alguém cometerá equívoco se alegar que além do que teoriza a ciência, toda outra indagação é então mera aporia, mito, sonho e ilusão. É só ver que tudo aquilo que procede da teorização e verdade da ciência, como os produtos, a tecnologia, os 
novos modos de nutrição e de viver interferem no destino da realidade, sem se saber ainda o que ela é; dão a ele outro sentido sem saber qual é o seu verdadeiro sentido. Dito de outra forma, mesmo a verdade teórico-científica não responde pela verdade que é sentido filosófico da realidade em que nos encontramos.

A experiência cotidiana (correspondente ao pastor) e a científica (correspondente ao cientista) relativamente ao sol aparecem aqui com o valor de ilustrarem e exemplificarem a instância (desconhecida ou ocultada) de onde parte a singularidade da coisa, nas coisas. A rigor, é tal instância que interessa como questão. Por isso e para isso - quer dizer, para tornar mais claro isso - é que aparecem esses exemplos. Razão porque o autor recorre a um parêntese para mostrar os exemplos, dizendo assim: "Antes de prosseguirmos no curso do nosso questionar é necessário fazer um parêntese para dizer algo acerca da nossa experiência quotidiana” (HEIDEGGER, 1962, p. 9). Isso significa, portanto, que após a ilustração feita, o que vai prosseguir como desenvolvimento da questão é o que predomina como conteúdo nesse assunto do conhecimento filosófico.

Tendo em vista este marco do que vai continuar depois da ilustração, devemos vê-lo como sendo aquilo que Heidegger está a caracterizar enquanto a instância de onde as coisas obtêm sua singularidade, e que, no momento, ele dá o nome de "aí". Este "aí" está a significar o âmbito, muito enigmático e ainda não bem definido, do qual, porém, a singularidade das coisas provém. O que está em jogo ou em questão, portanto, nessa expressão "coisalidade da coisa", se iguala a esta instância, a este "aí" - onde se acham todas as coisas e também, implicitamente, a coisalidade da coisa efetiva.

Sendo assim, devemos seguir o autor no que respeita ao parêntese e alcançar logo o ponto em que este é fechado. Devemos fazer a ponte que liga o que foi dito aqui sobre esta instância e o que dá continuidade a isso, no ponto em que o parágrafo é concluído. Trata-se do que aparece fazendo evoluir a razão de ser da singularidade das coisas como o "cada coisa" nas coisas. Esse novo elemento na evolução da questão surge como a discussão sobre tempo e espaço: na discussão sobre "o que é uma coisa", teria sido empregado o significado de espaço e de tempo para desenvolvê-la, expressá-la e defini-la.

Passa a ser necessário indagar novamente o que teria sido compreendido por espaço e tempo em relação à questão em curso. O que resulta agora daquilo que foi compreendido? Em que estágio se encontra agora a questão, relativamente a isso? A resposta demanda atenção ao que o autor quer dizer por tempo e espaço. 
Seguindo o curso do texto, somos levados a vincular tempo e espaço e o que está em jogo na definição de sol que depreendemos a partir do pastor e do cientista. De saída tende a predominar como verdade na definição do sol as condições e possibilidade de se dizer sol como um determinado sol, como uma coisa singularizada, como "este" sol, como "esta" coisa determinada e não uma aparente, sonhada, poetizada, ilusória. Mas o ponto fundamental relativamente a essa definição - o que estamos tomando como condutor do tema em estudo, a saber, o conhecimento filosófico -, foi apresentado por Heidegger aqui como certa conjuntura ou âmbito de nossa experiência, de tal maneira que isso se faz presente na experiência do pastor e também na do cientista e por extensão, está em toda e qualquer experiência; mas também, de certo modo - quer dizer, por causa disso - não é o que diz o pastor nem o que diz o cientista nem o que dizemos nós, quando definimos o que seja nossa experiência. Mesmo assim, este ponto fundamental foi apresentado como sendo tudo isso, enquanto nossa experiência e, por isso, foi nomeado assim: é simplesmente aquilo que está sempre aí vindo até nós. É um ser-aí. Deste "aí" provém tudo o que constitui "Nossa experiência e nossa opinião cotidianas das coisas" (HEIDEGGER, 1962, p. 9).

Para examinarmos como é que tempo e espaço estão vinculados a esse ponto fundamental devemos pôr em destaque uma afirmação de Heidegger, na orientação desse entendimento. Desfavorecendo o modo de conhecer que tende a predominar na questão - o modo de conhecer do cientista -, Heidegger diz que quando se visualiza a questão, não a partir do quadro [espaço e tempo] em que elas [as coisas singularizadas] aparecem, então "não é cada coisa, necessariamente, 'esta' [coisa] inconfundível”' (HEIDEGGER, 1962, p. 17).

Isto quer dizer que, em princípio, é graças a tempo e espaço que resolvemos o impasse relativo à singularidade das coisas, pois graças a esse recurso conseguimos que uma coisa não seja outra nem que haja 'duas coisas iguais'; ou seja, tal fato não poderia ocorrer no mesmo espaço e ao mesmo tempo. No entanto, a questão não termina depois disso e, nesse sentido é que se vincula ao ponto fundamental do âmbito do aí, - não termina porque, se quisermos, podemos admitir que, justo quando nos certificamos da singularidade da coisa como esta determinada coisa, nisso mesmo é que vemos que este "esta" da singularidade não está na coisa propriamente e sim no nosso comportamento em relação a ela; é quando nós indicamos este "esta" nesta ou naquela ou naquela outra referência. O "esta" concerne a essa "indicação" que parte de nós; não parte da singularidade da coisa que a relação tempo e espaço promove no aparecimento dela. $\mathrm{O}$ "esta" concerne, pois, ao aí como o nexo desta ou daquela referência indicada no encontro relativo à vinda da coisa até nós. 
A partir desse entendimento, esse aí enquanto o nexo da indicação das referências é que passa a ser base de explicação de por que tempo e espaço são recorridos para se assegurar a singularidade de uma coisa. De um lado, nós queremos a todo custo justificar a verdade de que não há uma coisa igual a outra. Mesmo em coisas idênticas e da mesma espécie, uma não é igual à outra. Surge-nos o elemento que, com toda propriedade, pode ser a base dessa verdade. Trata-se da existência da relação tempo e espaço. Mesmo nos restringindo à noção mais elementar de tempo e espaço, isso já indica esta base para verdade. É o caso de se dizer que devido ao espaço em que uma coisa está não pode ser ele o mesmo ocupado por outra. Então, até mesmo se uma coisa fosse totalmente igual à outra, ainda assim se distinguia da outra, devido à posição de cada uma em relação ao espaço. De modo semelhante constata-se a diferenciação entre uma e outra em relação ao tempo. É o caso de se dizer que ainda que uma coisa pudesse ocupar o mesmo lugar de outra, tinha de ser em momentos de tempo alternados, diferentes.

Mas se é verdade que as coisas se diferenciam necessariamente na base de tempo e espaço, isto não quer dizer que, com isso, o tempo e o espaço tenham sido compreendidos e explicados quanto a sua proveniência, só porque estão sendo essa base de se poder ver uma coisa como "esta" coisa. Não se explica, por exemplo, onde encontrar os aspectos exterior e interior que mostram, respectivamente, espaço e tempo. Ou seja, temos de usar a ideia de exterior e de interior a partir de algo familiar, para dizer qual verdade espaço e tempo dão a uma coisa. Por isso procuramos, mas não encontramos a espacialidade na exterioridade nem a temporalidade na interioridade. Temos de admiti-los como certo poder, certa possibilidade. E ainda que chegássemos ao ponto de reduzir a espacialidade à própria extensão das coisas, dando com isso mais poder ao tempo, ainda assim não encontraríamos o tempo. Não o encontraríamos nem no passar dos fatos no espaço de tempo nem dentro do relógio nem no "Observatório" que convenciona todo o tempo que utilizamos quando da comunicação. Resultado: "[...] não é uma questão das ciências da natureza; mas sim [esta questão] está, propriamente, em questão $n a$ questão se e como nós somos ainda solicitados pelo sendo enquanto tal na totalidade" (HEIDEGGER, 1962, p. 39).

Devido à novidade em relação à compreensão deste “aí”, enquanto "ser-aí”, Heidegger destaca a particularidade com que Leibniz compreende a singularidade da coisa. Mas inclui a compreensão leibniziana na mesma concepção de como se tem pensado o ser da coisa. Se em Leibniz é Deus que aparece como fundamento e base da diferenciação do ser de cada coisa, este ser permanece pensado, no entanto, como sendo identidade de uma coisa, diferenciada, 
porém, da identidade da outra coisa. Heidegger declara: "Da indicação de Leibniz resulta que a característica da coisa, de ser 'esta', pode ser também fundamentada de outro modo, a partir do seu próprio ser e não apenas pela referência à sua localização espácio-temporal" (HEIDEGGER, 1992, p. 33).

Em outro momento ${ }^{3}$, sete anos antes de dizer isto, Heidegger trata de mostrar que Leibniz decide a compreensão da verdade a partir da relação predicativa de sujeito e objeto, embora para poder dizer de uma concordância entre cada coisa e sua identidade originária, precisando permanecer sempre unidas e interdependentes. Esta identidade originária, que aqui tomamos enquanto Deus, é compreendida e justificada como medida de "razão suficiente", na forma de sujeito que contém e detém o predicado. Nesta condição, esta medida para verdade tem força e conteúdo de princípio racional para definir o que é cada coisa. Mas, visto de outra perspectiva, o que define tal princípio é o fato de ele ser obrigado a existir: este princípio porta subjacentemente a convicção de que sem esta medida racional para verdade, "haveria entes que seriam necessariamente sem fundamento" (HEIDEGGER, s/d, p. 19).

Razão porque o princípio chega a ganhar formulações nestes termos: “"nada existe sem razão’ ou não há efeito sem causa'” (HEIDEGGER, s/d, p. 19).

Isso indica que Leibniz pode se livrar daquela relevância própria de tempo e espaço, porque toma como verdade aquilo que não permite (suporta) outras verdades que comprometessem "a 'natureza' da verdade em geral" (aqui, Deus). Antes, o que deveria ser é que cada ente se une à sua identidade originaria e verdadeira (Deus), de maneira que, no que se une, também se singulariza como o próprio ente. Mas, para Heidegger, a predicação própria da relação sujeito e objeto, que torna isso possível, já pressupõe, sem que se perceba, um mais originário "processo de revelação" disso. A verdade conseguida com a proposição relativa ao sujeito e predicado já seria anterior e propiciadora do processo dessa revelação. Heidegger afirma aí: “Assim, por exemplo, a verdade do que está simplesmente presente (por exemplo, as coisas materiais), enquanto descobertura distingue-se especificamente da verdade do ente que nós próprios somos, da abertura do estar-aí (Dasein) existente" (HEIDEGGER, s/d, p. 21-23).

Esta declaração de Heidegger de anos antes coincide, porém, com o que ele quer dizer aqui pela singularidade, pelo "isto", dito por ele como "o que está aí": "O “isto' significa rigorosamente na proximidade imediata, enquanto, através de 'aquilo', visamos qualquer

\footnotetext{
${ }^{3}$ Referência à obra Sobre a essência do fundamento [Vom Wesen des Grundes] em relação à obra A questão da coisa [Die Frage nach dem Ding].
} 
coisa que está longe, mas também ainda no âmbito do aí e do ali - este aí, aquele ali" (HEIDEGGER, 1992, p. 19).

É útil aqui não se perder de vista o fato de que a vinculação que Heidegger estabelece, o mais estreitamente possível, entre a singularidade e este âmbito do aí tem em mira poder dizer verdade no conhecimento filosófico: aquela questão a implicar o sentido de conteúdo filosófico que representa Tales cair no poço e, ao mesmo tempo, a criada conseguir fazê-lo estar, em última instancia, no seu ponto mais extremo - no âmbito das coisas mais próximas de nós. O conteúdo disso aparece distinguido e assegurado por Heidegger em forma de indagação: "[...] como nos é possível saber algo da verdade própria sobre a coisa, quando não conhecemos propriamente a coisa, para decidirmos que verdade lhe pode e precisa ser atribuída?" (HEIDEGGER, 1962, p. 20).

3.

Em mais um passo no desenvolvimento do assunto posto convém repetir a afirmação de Heidegger pela qual certo paradoxo torna mais destacado o conteúdo da questão 'que é uma coisa':

No que questionamos assim, buscamos algo que faz em uma [coisa] tal, a coisa enquanto coisa, não enquanto pedra e enquanto madeira; algo que torna coisa (bedingt) a coisa". [...]

E, no entanto, pomos esta questão apenas para saber o que é uma pedra, um lagarto, que toma sol em cima dela, o que é um broto de grama, que cresce ao lado, o que é um canivete que nós, deitados no prado, temos na mão talvez" (HEIDEGGER, 1962, p. 7).

Conforme se vê, Heidegger faz referência ao "modo" de investigar - fala do tipo de "investigação". O referido paradoxo diz bem este "modo" próprio de investigar: em primeiro olhar, o investigar vale para a verdade da singularidade - para uma planta, um animal, um astro, etc.; mas, para o conteúdo essencial, o investigar se exclusiva e vale para dizer o ser e, com exclusividade, dizer que interessa investigar "apenas" o que é já determinado como coisa, a coisalidade. Trata-se de dizer o que já se pôde antecipar a isso e ser nisso a verdade. Isto soa agora assim: esta questão não teria sentido nem existiria caso não fosse exclusivamente para a comunicação humana entre pessoas e coisas, apesar de que sempre tem de ser e de parecer que é "apenas para saber o que é uma pedra, um lagarto [...] um broto de grama $[\ldots]$ um canivete $[\ldots] "$

A partir daqui se requer dar atenção ao recurso utilizado para mostrar a compreensão, que se consegue aos poucos, do que diz Heidegger sobre a coisalidade. No caso, destaco dois elementos da afirmação de Heidegger citada acima, para objetivar melhor o conteúdo do 
caráter histórico na questão. Um deles é o "modo" de investigar, referido acima - na medida que "questionamos" deste determinado modo. (HEIDEGGER, 1962, p. 7). A pergunta subentendida e subjacente vale ser trazida à tona, porque destaca e faz gravar o conteúdo implícito na resposta também subentendida: Heidegger fala de algo que é ao mesmo tempo "antigo", mas também "novo", por se "repetir" sempre e ineficaz, porque aí "nada pode começar"! Tal "modo" de ser nesta questão significa que mesmo que não nos interessemos por ela nem nos despertemos para ela, ainda assim tudo seguirá seu curso de efetivação: "sem ela, os planetas continuam a percorrer as suas órbitas" e "o elã da vida continua a pulsar através dos animais e das plantas" (HEIDEGGER, 1987, p. 36); mas isto quer dizer simplesmente que ela, em certo sentido, preexiste a nós. Tal sentido coincide com o conteúdo de histórico que, por esta razão, não quer dizer exatamente relativo a tempo passado ou atual; quer significar algo mais que isso enquanto o que é desde sempre.

O outro elemento presente na referida afirmação é o conteúdo de "aquilo que torna coisa a coisa”. Esta centraliza a noção principal do conteúdo em desenvolvimento referente à questão: tal conteúdo é o próprio caráter de histórico, ora referido. Deve ser lembrado que Heidegger informa, já no primeiro parágrafo de seu texto, que a questão da coisalidade é "antiga" e que, ao mesmo tempo, precisa-se considerar que ela é "nova", em razão de ser colocada sempre mais uma vez. No decorrer do texto ele deixa sobressair que isso a torna atual. Podemos entender que é nisso que esta questão passa a ser concebida e definida como tendo de ter um "caráter histórico". O conteúdo disto sintetiza o essencial daquilo que tem sido dito até aqui e o que segue no sentido de sua conclusão. De modo mais preciso, ele diz pois o que devemos entender por isto: trata-se de certo "pôr em movimento o íntimo acontecer inicial desta questão", o qual, porém, deve ser procurado e encontrado por nós "aí, em cada proposição, em cada opinião cotidiana, em cada aproximação em direção às coisas" (HEIDEGGER, 1992, p. 54).

O conteúdo de histórico, como se pode notar, passa a predominar como base de explicação da questão da coisa. Mas também é importante passar a ver vinculada a isso a compreensão do conteúdo da verdade. O que se deve ver é, de um lado, não ser suficiente deixar permanecer a "essência da verdade" em algum tipo de "adequação" ou "concordância"; de outro lado, isto significa poder reconhecer como possível vincular o conteúdo da verdade à condição de "desvelamento", pois a relação entre ser a questão "antiga" e igualmente "nova" ou atual não concerne a tempo e espaço nem ao caráter de objetividade. 
Importa destacar isso assim, para ressaltar que a explicação da verdade da coisalidade da coisa ainda não teria sido concebida desse modo. Desde Platão e Aristóteles, a verdade da coisalidade se encontra no dizer, que é enunciado na proposição sentencial sobre uma coisa. Mas uma coisa é o que está de acordo com a sua essência, ou seja, segundo o conhecimento estabelecido pelo sujeito que conhece. Isso segundo uma estrutura de compreender que assegura um grau de validade a que nada possa escapar quanto à sua definição ou essência.

$\mathrm{Na}$ modernidade, tal validade é reassegurada pela relação sujeito e predicado nas proposições ou juízos. Neste caso, a verdade se conserva como a adequação ou conformidade graças a essa relação. Mas, justo o conteúdo da verdade da coisa faz o diferencial entre o que Heidegger defende e o que diz a tradição. Em outros termos, o caráter histórico da coisalidade não comporta a verdade como adequação ou conformidade. Seu outro sentido de verdade, agora em consonância com o conteúdo de histórico, Heidegger retém dos gregos, retomandoo do termo alétheia. Trata-se do simples desvelar da coisa como ser-aí. Verdade é desencobrimento. A história, enquanto passado e acontecimento nos serve, agora, tanto para não aceitá-la mais enquanto o passado, quanto e, sobretudo, para não negar, por esta razão, sua existência; não negá-la como outro modo de ser. O acontecimento nos diz o modo de a efetividade ser enquanto "repouso".

Deve-se destacar, neste sentido, o conteúdo que sustenta a indagação feita por Heidegger sobre a "verdade" na forma e argumento seguintes: ao mesmo tempo que queremos dizer a verdade relativa a determinado ente em questão, afirmamos que não conhecemos tal ente. "[...] como nos é possível saber algo da verdade própria sobre a coisa, quando não conhecemos propriamente a coisa, para decidirmos que verdade lhe pode e precisa ser atribuída?" (HEIDEGGER, 1962, p. 20).

Qual o conteúdo da verdade neste caso e de que fonte ele procede? Há dois aspectos nesta indagação que convém distinguir, na tentativa de se entender melhor o significado mais fundamental da declaração no seu todo. Primeiro aspecto: não conhecemos o ente, do qual queremos obter a verdade. Segundo aspecto: precisamos da verdade, porque é ela a condição de conhecermos o ente e dizermos o que ele é.

Certo impasse e paradoxo aparecem ganhando força mais e mais. Passa a haver uma espécie de necessidade intrínseca a si própria, no sentido de se costumar dizer que não poderia haver algo sem uma causa. Do contrário, teríamos de manter uma incongruência e convivermos com ela: ao mesmo tempo que queremos provar que não podemos alcançar a verdade, precisamos também contar com aquilo, sem o qual não podemos provar o que 
queremos provar. Este "aquilo" seria a própria verdade - que teria de existir, mas conforme já foi dito, não seria possível de ser alcançada.

Uma solução fácil - mas simplista - seria recorrer ao que o impasse determina como algo evidente. Seria de se dizer: a verdade se impõe como aquilo sem o qual nós nos mantemos numa contradição. A contradição consiste em afirmar conhecer e simultaneamente afirmar que não se pode conhecer.

A problemática construída por Heidegger em relação a isto deve nos conduzir para outra saída, diferentemente desta da mera lógica do impasse. Ela aponta para as duas coisas que interessam aqui: uma é entendermos o que Heidegger quer dizer por isso; e a outra é vincular esta problemática ao propósito do tema em estudo que é o significado do saber filosófico na questão da coisa, independentemente de coincidir ou não com a concepção de Heidegger. A ideia aqui é que temos de nos interessar por esta concepção, achando que deve coincidir de alguma forma com aquilo que precisamos para levar adiante o tema em debate.

Mas voltemos ao "impasse" mencionado; convém concluir o comentário sobre a solução simplória, formulado nos termos de que o sujeito que conhece não tem como negar que pode alcançar a verdade. Este argumento quer dizer o seguinte: $O$ que o sujeito ainda não sabe é como ele conhece e como estabelece a objetividade referente ao ente que quer conhecer. De forma que a singularidade do ente depende de uma determinada estruturação da relação entre a coisa conhecida e o sujeito que a conhece. Isto dá outra providência para a relação entre a subjetividade e a objetividade referentes a como se conhece. Nessa relação, a objetividade é dada em razão de como o sujeito conhece. A noção de objetividade está presa à compreensão da coisa como "esta" coisa, no sentido de algo lançado diante do sujeito que a apreende.

Se se sai dessa lógica do impasse, vê-se que Heidegger mostra a relação de 'objetividade' com 'subjetividade' dando a entender que a compreensão da verdade aí está vinculada ainda diretamente à dependência de tempo e espaço. Basta que se desfoque esta dependência, para que a verdade se torne a não-verdade. Consideremos um exemplo de juízo como este: "“aqui está o giz"”, de modo a corresponder a determinado lugar e objeto. Fora desta situação - lugar e objeto - o juízo se torna falso, a verdade se torna não-verdade. $O$ mesmo pode ser constatado em relação a tempo, como em outro juízo: “"agora é meio-dia"”. Fora do momento correspondente, a verdade se torna não-verdade.

Na reflexão deste tipo sobre o que é a coisa estamos na altura em que concluímos os vários modos de nos referirmos ao "isto" próprio à singularidade de uma coisa, segundo o 
exame daquelas "propriedades" que a mostram assim singular; estamos, pois, na altura de nos referirmos a uma coisa segundo outro aspecto igualmente legítimo, de como a coisa se apresenta como algo singular. Precisamos nos referir a essas propriedades, mas agora segundo o suporte em que se sustentam e se determinam como coisa. Heidegger se refere a este significado de suporte de propriedades (Cf. HEIDEGGER, 1962, p. 25-26), mostrando dois aspectos importantes da reflexão: 1) Em uma referência à Crítica da razão pura, ele destaca o seguinte: toda coisa é aquilo que permanece como a coisa que ela é e, ao mesmo tempo, isto mesmo que ela é (que permanece) é o modo de suas propriedades poderem levar aquela coisa a ser isto que ela é. Neste primeiro aspecto, aquilo que permanece - o suporte de propriedades - está a equacionar uma dificuldade que se arrastara até Kant, que é podermos assegurar a essência metafísica da singularidade da coisa, mas sua condição de princípio sendo gerada pelas propriedades que formam a "natureza". 2) No entanto, certa prioridade que é dada aí à natureza das propriedades das coisas não é inerente à natureza dessas propriedades como aparenta ser. Ao mesmo tempo que caracteriza a exigência da modernidade como metafísica da representação, também indica que se trata de algo que exprime o pensamento de Platão e Aristóteles bem como toda a tradição.

Heidegger unifica os dois aspectos e nos leva a perceber que ele extrai daí um terceiro, que é a constituição histórica da coisalidade da coisa: tanto no sentido de sua historiografia, como no sentido de que a historiografia oculta ou esconde algo que faz com que a coisa seja suporte de propriedades. Este ocultamento/velamento histórico, assegurado assim pelo suporte de propriedades, revela - como que sem esta intenção - um desvelamento que não se definiria mais pela condição de suporte de propriedades.

Estes dois elementos são aquilo que vemos constituindo o entendimento heideggeriano na condução da questão "que é uma coisa". Isso significa que o nosso entendimento daquilo que Heidegger continua a falar sobre esta questão demanda nossa observação de um elemento e do outro: do velamento e do desvelamento. Na continuação da leitura do texto, podemos nos fixar nesses dois aspectos para receber as informações que seguem sendo fornecidas por Heidegger. Por exemplo, a partir destes dois elementos destacam-se o significado da verdade como adequação e sua nova compreensão como desvelamento. Como também aparece a necessidade de se distinguir entre a historiografia, concernente ao suporte de propriedade, e a historicidade, concernente àquilo compreendido como desvelamento. 
Novamente então passa a ser um problema o modo de se assegurar a verdade, demandando, portanto, a retomada do âmbito a partir de onde se pode falar da verdade, sem restringi-la à singularidade da coisa.

Se examinássemos a procedência do suporte de propriedades no que diz respeito aos vários modos subsequentes de suas versões, mesmo como formas de oposição a ele próprio, perceberíamos que falhamos no reconhecimento de sua gênese. Por causa disso falhamos também na compreensão do dizer que diz qual questão e que verdade lhe são inerentes. Quer dizer: a modernidade não resulta em oposição a Platão e Aristóteles e à tradição; seria o contrário: seria preciso ver para onde e para o que indicava a questão na época daqueles filósofos. Um ponto marcante aí seria o fato de Protágoras definir o dizer a verdade como respeitante ao homem, no sentido de "medida" das coisas. Isso não deveria ter evoluído no sentido de levar o dizer (a proposição) e a verdade para a objetividade da relação sujeitoobjeto da modernidade, e sim para o significado grego de verdade como alétheia. Mas como se evoluiu no equívoco, então também se assegurou esse mesmo equívoco ao se achar que tomamos a verdade a partir das coisas e não a partir da proposição (do modo de dizer). Com a compreensão do suporte de propriedade percebemos o referido engano. Donde se percebe agora que a compreensão da verdade, que se estabeleceu como conformidade ou adequação, deveria ter-se estabelecido em consonância com a alétheia, e por isso seria não adequação, mas desvelamento.

Heidegger trata da questão "que é uma coisa" buscando sempre indicar a proveniência daquilo que decidiu que esta questão seja uma questão. Isto interessa no que concerne ao elemento fundamental do conhecimento filosófico, porque trata do que significa ser primeiro ou começo ou origem. Acompanhando esta reflexão de Heidegger, chegamos à altura em que ele chama de "suporte de propriedades" aquilo que agora passa a ser o que diz a coisa em sua singularidade. Ele descreve o denominado "suporte de propriedades" da seguinte forma: (1) apontamos como determinação de uma coisa aquele conjunto de qualidades ou propriedades que a coisa porta ao se apresentar a nós; assim como quando dizemos "uma pedra", referimonos a sua dureza, sua aspereza, sua cor cinzenta, sua forma irregular, seu peso característico. Quando dizemos "uma planta", referimo-nos a algo que possui raiz, folhas e coisas desse gênero dos vegetais. O mesmo procedimento aplicamos para quando dizemos "um relógio", no sentido de nos referirmos à sua engrenagem mecânica, os mostradores do tempo etc. Tratase das propriedades ou qualidades de uma coisa como tal coisa. (2) Assim temos cada coisa em sua singularidade, isto é cada coisa é diferente da outra e, no entanto, é sempre um mesmo 
elemento que permite esta singularidade de cada uma, segundo suas qualidades ou propriedades. Este mesmo elemento é o "suporte", mediante o qual as diferentes propriedades podem singularizar cada coisa. Por isso, Heidegger o define como algo que "permanece" e que "é o mesmo aquilo a que sempre regressamos quando queremos fixar as "propriedades"; enfim é algo que "subjaz às qualidades" ou "propriedades". Este algo faz com que cada coisa seja suas próprias qualidades ou propriedades. (3) Podemos dizer então que este algo é, no caso, "suporte" ou "centro" ou o "em si" ou enfim, "o ser" de uma coisa concernente a suas propriedades.

O que é dito assim sobre as coisas não seria um dizer restrito à filosofia. Ou seja, o que é dito assim sobre as coisas define a natureza como sendo, esta natura as propriedades das coisas, e como sendo, portanto, o próprio mundo dessas coisas. De forma que quando a filosofia se refere a isso, apenas caracteriza seu campo de conhecimento, segundo seu modo típico de ser, que é o referir ao ser de alguma coisa - no caso aqui -, ela se refere ao ser da natureza; é o ser desse mundo das coisas. ${ }^{4}$ Tal ser, nessa situação está a coincidir com o "suporte" das propriedades das coisas. A filosofia é o dizer como a natureza é a natureza que está sempre sendo ela própria. A natureza seria o modo como são possíveis as propriedades das coisas a assegurar as coisas correspondentes. Este modo como as propriedades das coisas são possíveis enquanto permanência das coisas como estas coisas, é o que se chama "suporte".

Mas o jeito como o "suporte" é apreendido e empregado o torna apenas outra denominação para o que já existia enquanto "substância", "sujeito", posição. A partir daí pode-se perceber que, na definição do mundo como natureza, não são essas tais propriedades ou qualidades naturais das coisas que detêm sua verdade de serem assim como são. Sua verdade é definida como entidade metafísica, como o suporte ou a substância ou o sujeito e não como natureza ou algo natural. A verdade é definida como uma metafísica "adequação", "conformidade", "correspondência" entre as "propriedades" das coisas e seu "suporte" correspondente. As "propriedades" continuam sendo o mesmo que desde o começo da filosofia como metafísica, no sentido de serem o "mutável" em relação ao "suporte", que é “imutável". O sentido de toda a cientificidade da ciência moderna revela-se nisso, por fim, como modo específico da metafísica ser metafísica. É que o conteúdo de verdadeiro, que a

\footnotetext{
${ }^{4}$ Isso soa significativo em relação a Kant, no sentido de ele não empreender pôr em questão a "coisalidade". O fato de tomar a "determinação" mesma da "essência da coisa" enquanto "natureza", a coisa passa a ser tratada como "objeto da ciência físico-matemática". (HEIDEGGER, 1962, p. 100). Kant teria compreendido "“coisa' como o objeto de nossa experiência" e nisso precisando desde já haver separação entre "a coisa como se apresenta a nós", (in der Erscheinung) e a 'coisa em si' (HEIDEGGER, 1962, p. 100)
} 
ciência precisa para fazer qualquer afirmação, advém daquele suporte de propriedades das coisas.

Com isso vê-se que o sentido de "natural" e "natureza" para o mundo das coisas já não é o que responde pelo sentido de sua verdade e sim o que precisou ser tomado como para além disto, como o imutável metafísico - denominado aqui de "suporte de propriedades".

Do ponto de vista da lógica da reflexão em curso, passa a ser necessário que agora se ponha sob a forma de questão o conteúdo de "natural" e "natureza". Heidegger tem em vista que o que dizemos "natural" advém de uma concepção humana disto. Quer dizer, o que vem a ser considerado natural numa situação ou para alguém ou para uma cultura, não o seja numa outra situação ou para outrem ou para outra cultura. Em suma, o que se mostra natural o é só enquanto um modo de o homem conceber o que está-aí vindo ao encontro de quem o percebe como tal. Neste raciocínio é dito por Heidegger que o 'natural' tem sempre um caráter histórico (ist immer geschichtlich) (HEIDEGGER, 1962, p. 30). A determinação da coisa passa a ter um caráter histórico.

Heidegger estabelece uma medida crítica para o tratamento da questão. $\mathrm{O}$ caráter crítico diz que está equivocado o tratamento que não consegue tirar a questão do "repouso" em que ela se encontra enquanto "suporte de propriedades". O sentido de historicidade será dado justo por tirar a questão daquele "repouso" em que fora aprisionada. Mas, isso não pode sobretudo significar visar a um começo relativo ao tempo cronológico-historiográfico a se resgatar. Não há nada a ser resgatando assim como tal começo. Começo tem de significar "nós", o homem, no que concerne a se tomá-lo como portador desta questão, ainda que podendo julgá-la como suporte de propriedades. O deslocamento, enfim, interromperia de uma vez por todas essas tentativas de momentos historiográficos de se fazer a questão repousar em suporte de propriedades. Historicidade quer dizer agora o estar-aí inerente ao homem em cada situação vivida e cotidiana. Seria preciso agir correspondendo a isso.

A partir disso é que a determinação da coisa passa a ter um caráter histórico. Este marco, relativo ao sentido de histórico, é que passa a ser examinado e pensado agora. Devemos lembrar como Heidegger chegou até este ponto: foi partindo do exame do que fora tomado e compreendido por "natural”. A contestação de Heidegger de 'natural' se apoia no fato de que o que é natural para uma situação ou para alguém ou época etc., não o é para outrem. É daí que ele deduz o natural como procedente da existencialidade do vivente numa determinada situação. Histórico concerne a esta condição inaugural ou originária ou inédita. 
Já a partir disso, dessa compreensão de natural, precisa ser também entendido que uma explicação do sentido de histórico não pode coincidir com a do sentido do passado factual; o histórico não se refere ao que passou e deixou seu registro. Tal registro que a história apresenta não é suficiente para definir o conteúdo de sentido histórico. Na continuação deste argumento, Heidegger afirma que "ao nos dirigirmos às coisas", achando que isto consiste no que tomamos por "natural", na verdade "não somos nós que vemos ou falamos, mas uma antiga tradição histórica" (HEIDEGGER, 1992, p. 46/7). Precisávamos já nisso refletir e perguntar por que não se toma isto pelo que tem aí de histórico. Teríamos aí uma conexão originaria entre o homem e seu mundo. Por isso Heidegger diz que "falta, verdadeiramente, uma relação originária com as coisas e que tal relação se torna apenas ilusória com o progresso das descobertas e com os resultados da técnica" (HEIDEGGER, 1992, p. 47). O domínio exercido pela relação entre liberdade e decisão é que porta o conteúdo de sentido histórico: é o aí que decide como tudo tem de funcionar e passar a ser - até mesmo a criação e modo de funcionar dos "trens e motocicletas". Seria isto o fundamental, mas que é sempre singular em cada tempo e situação; singular quer dizer: conforme o domínio de liberdade e “decisão" de um “povo”. Isto é o caráter histórico.

Este ponto de vista teria de nos levar ao estado dessa crítica à compreensão da verdade da coisa, segundo uma falsificação de sua historicidade, no sentido de que em todos os modos de questionar, que fizeram essa história da coisa, em todos eles, é já a historicidade que fala antes.

Para finalizar o desenvolvimento deste assunto, o mais adequado aqui é, porém, não concluí-lo $\mathrm{l}_{2}$ a fim de permanecer em aberto o que ficou a caminho de ser melhor compreendido no escrito de Heidegger, lido para a presente abordagem. Ponho em destaque o próprio Heidegger denotar que podemos chegar a compreender o "caráter histórico" de modo equivocado: mais fundamental do que "o falar" dele na questão da coisa, seria, antes, "agir" (handeln) em relação a ela, de forma a corresponder ao conteúdo de "histórico" (HEIDEGGER, 1962, p. 41). Neste sentido temos de considerar que se chegarmos a demonstrar o conteúdo de "histórico", estaremos, a pesar disso, também ainda na condição de não compreendermos o seu significado. Combina com isso o fato de Heidegger, já no início de seu escrito, empregar esta comparação: de um lado, a tarefa da filosofia - luta pela 
“essencialização do ser"5 e dificuldade de compreensão disso -, comparando a atitude do que teria de ser um filósofo com a atitude de Tales de Mileto, de insistir em se voltar para as "estrelas", mesmo desafiando o "escárnio" da criada; de outro lado, o escárnio da criada, representando filósofos da história da filosofia, que não só não entram num empenho como o de Tales (relativo à "essencialização do ser") ou confundem isso, prometendo outra coisa e de modo equivocado e enganoso - mera "casualidade e confusão" (HEIDEGGER, 1962, p. 41).

Mas Heidegger se refere ao mesmo tempo ao que está a ser compreendido aí, ao caráter histórico, como "um questionar muito dificultoso e muito enfadonho, que permanecerá por decênios só um questionar" (HEIDEGGER, 1962, p. 32). Por este outro ângulo, então, é também como se este "agir" esteja sempre a informar igualmente que a explicação do conteúdo de histórico demanda um tempo ainda por vir para ser compreendida; como se dificuldades de acesso ao "caráter histórico" se juntam à importância de seu conteúdo. Então também assim, na razão de que mais adiante é que se pode compreender melhor o que está em questão, a relação Tales versus criada parece já não se fazer compreendida por nenhuma lógica do momento e sim só por uma forma de interpretação.

No que Heidegger precisa criticar a má compreensão do caráter histórico na questão da coisa, devemos frisar os elementos da declaração em que o fundamental é decidir pelo "como é no essencial ainda hoje", em vez de nos voltarmos para "o como foi outrora" (HEIDEGGER, 1962, p. 32). Nela é, pois, a noção de tempo que requer mais atenção. De um lado, a compreensão de tempo está a depender do conteúdo de "outrora", que implica o passado. De outro lado, a compreensão de tempo está a depender da operação que consiga distinguir entre "ainda hoje", que implica o atual, o presente e o que está para além disso, mas como o que se repete sempre - não exatamente como presente apenas nem já como o porvirfuturo.

Neste sentido devemos aludir ao fato de que o conteúdo do caráter histórico já se encontra tratado na obra fundamental de Heidegger, Ser e tempo. Isso mostra como o que aqui é tematizado por Heidegger como a questão da coisa já era na ocasião a mesma questão, embora tematizada então de maneira diferente desta. E nisso é significativo também que o conteúdo de "histórico" estivesse vinculado ao desenvolvimento do conceito de "historicidade". Sob este conceito, o conteúdo de sentido histórico exprime a necessidade de se compreender e admitir que nossa noção de tempo possa ser fundamentada no conteúdo de

${ }^{5}$ Convém aqui indicar o conteúdo da expressão "essencialização do ser" a partir da obra Introdução à metafísica [Einführung in die Metaphysik] e respectiva parte indicada com a paginação (Cf. HEIDEGGER, 1969, p. 103s.); mas isso não exclui os outros momentos e obras do autor em que se encontra também o conteúdo relativo a esta expressão. 
ontológico concebido a partir da possibilidade de novo modo de se compreender o conceito "ser". E justo em relação a isto devemos considerar a principal exigência contra qualquer “desorientação" na compreensão e leitura da questão da coisa: com esta questão "não se pode começar nada" mais (HEIDEGGER, 1962, p. 2). Dito de outra maneira: com esta questão partimos sempre do conteúdo da verdade e com isso não nos encontramos fora dele nunca. É que a verdade não se dá como "conformidade" de uma coisa em relação a outra (e a induzir relativa noção de começo), e sim como "desvelamento" daquilo que sempre já é, a saber, o "ser". Corrobora isto Heidegger dizer que, em seu escrito Sobre a essência da verdade, "se prepara, para o homem histórico, uma proximidade relativamente à verdade do ser" (HEIDEGGER, 1995, p. 65); mas seria também já o que ocorre em Ser e tempo: é “a verdade do ser procurada como fundamento de uma nova posição histórica..." (Ibidem, p. 65). Seria, pois, sob a mesma referência à "verdade do ser" que fora então instituída a caracterização analítica da "existencialidade" de mundo e homem.

Portanto, desde muito antes, o caráter histórico não seria "histórico" em razão de conteúdo algum de cunho historiográfico, ainda que assegurado sob a validade de "objetivação". A rigor seria o contrário disso, no sentido de que todo conteúdo de cunho historiográfico teria de ser denominado e compreendido assim, graças ao caráter já histórico intrínseco à coisalidade, mas isso quer dizer, enfim: devido à constituição ontológica na coisalidade, que concerne ao conteúdo da "verdade do ser".

Pode-se considerar com isso uma indicação já clara para Heidegger de que a história da filosofia se desviou frequentemente do elemento autêntico desta questão, mesmo que incluindo tentativas de autocrítica. Na presente abordagem, portanto, tornou-se fundamental considerar antes de tudo o que podemos deduzir da instrução que o filosofo fornece com o caráter de questão da coisa e, consequentemente, o desvio em relação a seu elemento essencial: o saber filosófico que possuímos já desde muito tempo atrás, na verdade não está dado como parece; antes está a resultar daquilo que se tem apreendido no embate das ideias em nossa busca por ele. Justamente aí, quando a filosofia já se toma como crítica moderna e contemporânea, o desvio não teria deixado de ser ratificado: o caráter histórico afastado de nós mesmos justamente quando supomos que já o detemos em nossa crítica à concepção de “coisa". Em outros termos, em atenção a Heidegger, deve-se saber como a questão da coisa precisa ser posta, para evitar não passar de "simples casualidade e confusão" e não permitir que ela "fique atolada sem saída" (HEIDEGGER, 1962, p. 41). 
Esta instrução de Heidegger tende a ser acolhida, porque possui grau de profundidade muito elevado a se considerar. Seu conteúdo revela isto, porém, pelo que se apresenta já explicado e porque também implica outra parte em que isso é muito mais só anunciado. Neste último aspecto reside, pois, o que se encontra "a caminho de ser melhor compreendido". Por exemplo, é dito acima: aquilo mesmo que já sabemos, no fundo, "não está dado como parece". Isso quer dizer que o caráter histórico concerne a um conteúdo pensado, mas que não se define pelo que apenas está dado como saber. O que implica significar também o seguinte: demanda que o criemos.

No entanto, o sentido de "criar" aparece subentendido e não se deixa mostrar diretamente. Determinada menção feita a Leibniz, por exemplo, encontra-se na indicação de ser mostrado o que vai além do que nos parece dado, isto é, sabido no "princípio de identidade dos indiscerníveis": duas coisas ditas iguais não seriam duas, mas uma única (HEIDEGGER, 1992, p. 32). À pergunta, "por que não?", teria como resposta: Seu criador, Deus, sendo perfeito, teria sua perfeição posta em dúvida ou falsificada. A atenção centrada em Deus na ocasião parece trazer para a questão a compreensão do aspecto teológico, mas não é isso o fundamental no caso; importa é o fato de tratar de "o ser da coisa" ser ao mesmo tempo o "seu ser-criado por Deus". Trata-se do elemento único que se encontra também em uma conhecida declaração atribuída a Leibniz: "“Por que há o ente e não antes o nada?"” Num caso e no outro, está em jogo conseguir perceber que - não se tratando mais da época de Leibniz e sim do século XX - quando a compreensão do ser da coisa não coincide mais com ser Deus seu criador, o ser da coisa teria de continuar, porém, pertencendo à "essencialização do ser", como a questão do compreendê-lo.

De modo subentendido, o que assume o lugar do poder de criar condiz necessariamente com a questão e "verdade do ser". Mas concomitantemente, Heidegger induz que há de se aguardar o tempo propício para o entendimento disso: "Ainda não estamos suficientemente preparados para tomar posição sobre o princípio expresso por Leibniz e sua fundamentação" (HEIDEGGER, 1992, p. 32). Assim aguarda ele também poder contar com mais recursos, ainda, para explicar melhor o conteúdo disto em jogo, embora se encontre desenvolvido em outras obras ${ }^{6}$.

A espera pelo tempo por vir como recurso para compreender o essencial em jogo permanece, pois, recíproca - para nós e para Heidegger. Como informa ele próprio, "ainda" não poderíamos já conseguir lidar com o pensar de uma forma tal que fôssemos capazes de

\footnotetext{
${ }^{6}$ Limito-me aqui às obras Sobre a essência do fundamento (Vom Wesen des Grundes), Introdução à metafisica (Einführung in die Metaphysik) e Sobre o humanismo (Über den Humanismus).
} 
efetivá-lo, ou seja, de lhe proporcionar o "livre acesso" (HEIDEGGER, 1979, p. 81). Também em uma declaração sua refere-se ao conteúdo em questão, indicando que demanda no mínimo "um século para ser decidida" e, além disso, se o século "não está adormecido nem julga, tampouco, que está acordado". O decisivo consiste em "se e como nós somos ainda solicitados pelo sendo enquanto tal na totalidade" (HEIDEGGER, 1962, p. 39).

Talvez só precisássemos discutir com Heidegger quanto ao "como" - de que modo - já estamos sempre a corresponder ao "sendo"-Ser. Por se tratar da "verdade do Ser", mas sem mais a condição "Criador"-“criatura", e sim o "litígio" por condição, abre-se espaço para se refletir sobre o alcance à diferença entre as duas condições e sobre a confiança na noção de quantum de tempo para tal coisa. Podemos indagar se não ocorre de uma coisa já se encontrar fundida com a outra, significando poder dispor sempre do já buscado antes: o belo, a felicidade, a graça, a iluminação, o bem supremo, etc.; ou se teria de ser outra coisa. Esta indagação apenas repete, para frisar e ficar do mesmo jeito, isto: aquilo que conhecemos "não é já o que parece" que sabemos. Aqui é que o distanciamento filosófico em Tales parece querer significar não só ultrapassar o próprio entorno, como ir até onde nenhuma coisa mais tenha "solo", "fundo" (HEIDEGGER, 1962, p. 7); o "escárnio" da criada parece antes não querer impedir buscar a beleza do céu, quando não se deixa seduzir por ela nem tender para ela. Assim também talvez se chegue a dizer por que o distanciamento filosófico não se permite deixar apaziguar a partir deste e neste próprio aqui.

\section{REFERÊNCIAS BIBLIOGRÁFICAS}

HEIDEGGER, Martin. A essência do fundamento. Tradução de Artur Mourão. Lisboa: Edições 70, 1987. (Edição em Alemão e Português) [Vom Wesen des Grundes. Vittorio Klostermann GmbH, Frankfurt am Main, 1949].

Die Frage nach dem Ding: zu Kant's Lehre von den transzendentalen Grundsätzen. Max Niemeyer Verlag, Tübingen, 1962.

Introdução à metafísica. $2^{\mathrm{a}}$ ed. Tradução de Emmanuel Carneiro Leão. Rio de Janeiro: Tempo Brasileiro, 1969. [Einführung in die Metaphysik. Max Niemeyer, Tübingen, s/d.].

O fim da filosofia e a tarefa do pensamento. Tradução de Ernildo Stein. São Paulo: Abril Cultural, 1979, p. 65-94. (Os pensadores).

Que é uma coisa. Tradução de Carlos Morujão. Lisboa: Edições 70, 1992. [Die Frage nach dem Ding. Max Niemeyer Verlag, Tübingen, 1987]. 
. Sobre a essência da verdade. Tradução de Artur Mourão. Porto: Porto Editora Ltd, 1995. (Edição em Alemão e Português) [Vom Wesen der Wahrheit. Vittorio Klostermann, Frankfurt am Main, 1976].

. Sobre o humanismo. $2^{\mathrm{a}}$ ed. Tradução de Emmanuel Carneiro Leão. Rio de Janeiro: Tempo Brasileiro, 1967. 2a ed. [Über den Humanismus. Da Francke A. C., Berna, s/d]. 